\title{
Nanoscale Organization of a Phthalocyanine-Fullerene System:Remarkable Stabilization of Charges in Photoactive 1-D Nanotubules
}

Dirk M. Guldi, ${ }^{\dagger, *}$ Andreas Gouloumis, ${ }^{\ddagger}$ Purificación Vázquez, ${ }^{\ddagger}$ Tomás Torres, ${ }^{\ddagger, *}$ Vasilios Georgakilas ${ }^{\S}$ and Maurizio Prato ${ }^{\S}$,*

${ }^{\dagger}$ Universität Erlangen, Institute for Physical and Theoretical Chemistry, 91058 Erlangen, Germany and University of Notre Dame, Radiation Laboratory, Notre Dame, IN 46556, USA

${ }^{\ddagger}$ Departamento de Química Orgánica (C-I), Universidad Autónoma de Madrid, Cantoblanco 28049 Madrid, Spain

${ }^{\S}$ Dipartimento di Scienze Farmaceutiche, Università di Trieste, Piazzale Europa 1, Trieste 34127, Italy

RECEIVED DATE (automatically inserted by publisher); E-mail: dirk.guldi@chemie.uni-erlangen.de; tomas.torres@uam.es; prato@units.it

Supporting Information Available

Table of Contents:

1. Synthesis of formylphthalocyanine 1

2. Synthesis of $\mathrm{ZnPc}_{-} \mathrm{C}_{60}$ system $\mathbf{8}$.

3. IR spectrum of compound 7 .

4. HPLC chromatogram of compound 7 .

3. Mass spectrum of compound $\mathbf{8}$. 


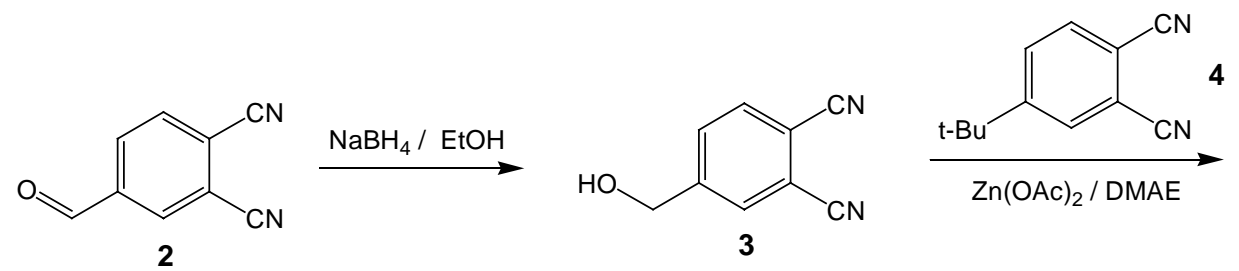

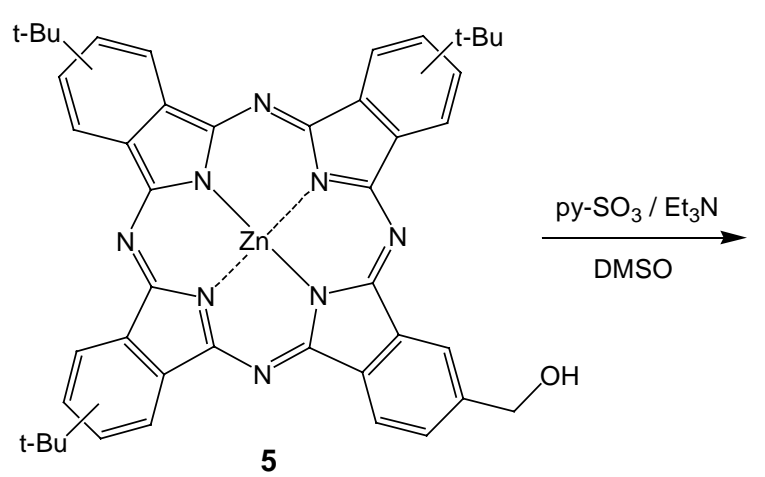

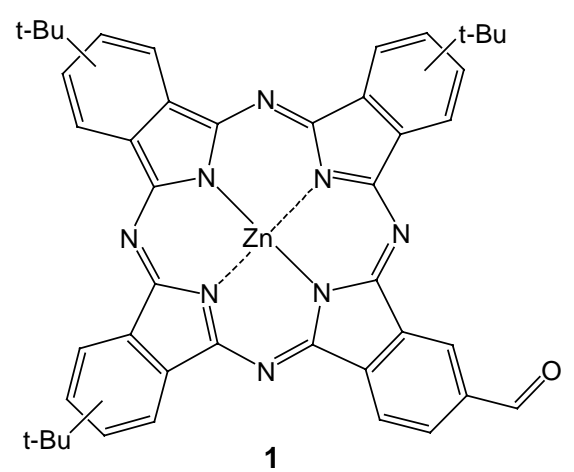

Scheme 1: Synthesis of formylphthalocyanine 1

4-Hydroxymethyl-1,2-dicyanobenzene (3). ${ }^{1}$ To a stirred suspension of 4-formyl-1,2-dicyanobenzene (2) (468 mg, $\left.3 \mathrm{mmol}\right)$ in ethanol (10 ml) $\mathrm{NaBH}_{4}(228 \mathrm{mg}, 6 \mathrm{mmol})$ was added and the resulting mixture was allowed to react at room temperature for $6 \mathrm{~h}$. After that time, the reaction was quenched with water $(10 \mathrm{ml})$ and extracted with $\mathrm{CH}_{2} \mathrm{Cl}_{2}(3 \times 20 \mathrm{ml})$; after drying $\left(\mathrm{NaSO}_{4}\right)$ the solvent was evaporated under vacuum. The title compound was obtained after flash column chromatography (ethyl acetate/dichloromethane 1:4) as a white solid, (460 mg, 98\%); m.p. 70$72{ }^{\circ} \mathrm{C} .{ }^{1} \mathrm{H}$ NMR $\left(300 \mathrm{MHz}, \mathrm{CDCl}_{3}, 25^{\circ} \mathrm{C}, \mathrm{TMS}\right): \delta=7.85$ (s, $\left.1 \mathrm{H} ; \mathrm{C}-3\right), 7.8-7.7(\mathrm{~m}, 2 \mathrm{H}, \mathrm{C}-5, \mathrm{C}-6), 4.84\left(\mathrm{~s}, 2 \mathrm{H}, \mathrm{CH}_{2}\right), 2.53(\mathrm{bs}, 1 \mathrm{H}, \mathrm{OH}) ;{ }^{13} \mathrm{C}$ $\operatorname{NMR}\left(75 \mathrm{MHz}, \mathrm{CDCl}_{3}, 25^{\circ} \mathrm{C}, \mathrm{TMS}\right): \delta=147.51(\mathrm{C}-4), 133.56,131.11,130.71,115.96$ and $115.40(\mathrm{C} \equiv \mathrm{N}, \mathrm{C}-1, \mathrm{C}-2), 63.08\left(\mathrm{CH}_{2}\right) ; \mathrm{IR}(\mathrm{KBr}): v$ $=3356(\mathrm{OH}), 3106,3071,3047,2230(\mathrm{C} \equiv \mathrm{N}), 1567,1381,1163,1097,852,749 \mathrm{~cm}^{-1}$; MS (EI) $\mathrm{m} / z(\%): 158(53)\left[\mathrm{M}^{+}\right], 141(100)\left[(\mathrm{M}-\mathrm{OH})^{+}\right]$; $\mathrm{C}_{9} \mathrm{H}_{6} \mathrm{~N}_{2} \mathrm{O}$ (158.16): calcd C 68.35, H 3.82, N 17.71; found C 68.08, H 3.86, N 17.57.

Tri-tert-butylhydroxymethylphthalocyaninatozinc(II) (5). A mixture of 4-tert-butyl-phthalonitrile (4) (737 mg, 4 mmol), 4-hydroxymethylphthalonitrile (3) $(158 \mathrm{mg}, 1 \mathrm{mmol})$ and $\mathrm{Zn}(\mathrm{AcO})_{2}(330 \mathrm{mg}, 1.5 \mathrm{mmol})$ in DMAE $(3 \mathrm{~mL})$ was refluxed during $24 \mathrm{~h}$. The solvent was evaporated under reduced pressure, and the crude product was purified by flash column chromatography $\left(\mathrm{SiO}_{2}\right.$, ethyl acetate/dichloromethane 1:4) to afford 5 as a blue solid $(170 \mathrm{mg}, 22 \%)$; m.p. $>300{ }^{\circ} \mathrm{C} ;{ }^{1} \mathrm{H}$ NMR $\left(500 \mathrm{MHz}, \mathrm{CDCl}_{3}, 25{ }^{\circ} \mathrm{C}, \mathrm{TMS}\right): \delta=9.0-7.0(\mathrm{br}, 12 \mathrm{H} ; \mathrm{Ar} \mathrm{H}), 5.0-4.8\left(\mathrm{br}, 2 \mathrm{H} ; \mathrm{CH}_{2}\right)$,

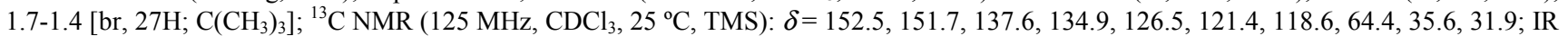
$(\mathrm{KBr}): v=3423,2955,1615,1458,1394,1331,1256,1144,1090,1048,922,879 \mathrm{~cm}^{-1} ; \mathrm{UV} / \mathrm{Vis}\left(\mathrm{CHCl}_{3}\right): \lambda_{\max } \mathrm{nm}(\log \varepsilon)=678(5.13), 616$ (4.18), 349 (4.71); MS (MALDI-TOF): $m / z:$ 776-778 [ $\left.M^{+}\right]$; $\mathrm{C}_{45} \mathrm{H}_{42} \mathrm{~N}_{8} \mathrm{Ozn}$ (776.26): calcd C 71.54, H 5.48, N 14.51; found C 71.08, H 5.49, N 14.20 .

Tri-tert-butylformylphthalocyaninatozinc(II) (1). To a stirred solution of tri-tert-butyl-hydroxymethylphthalocyanine $\mathbf{5}(78 \mathrm{mg}, 0.1 \mathrm{mmol})$ in dry DMSO $(4 \mathrm{ml})$ and triethylamine $(0.14 \mathrm{~mL}, 1 \mathrm{mmol})$ was added pyridine- $\mathrm{SO}_{3}$ complex $(100 \mathrm{mg}, 0.63 \mathrm{mmol})$ and the mixture was heated at $50{ }^{\circ} \mathrm{C}$ under argon atmosphere during 24 hours. After cooling, ethyl acetate $(50 \mathrm{ml})$ was added to the mixture and washed with water and brine. The crude product was purified by flash column chromatography $\left(\mathrm{SiO}_{2}\right.$, ethyl acetate/hexanes 1:3) to afford $\mathbf{1}^{5}$ as a blue solid $(65 \mathrm{mg}, 84 \%)$.

(1) Compound $\mathbf{3}$ was already described in the literature by reduction of 4-carboxymethylphthalonitrile without relevant characterization data: a patent, PCT Int. Appl.1998, CAN 129:109089. 
<smiles>CC(C)(C)OC(=O)NCCOCCOCCNCOC(=O)O</smiles>

1
6

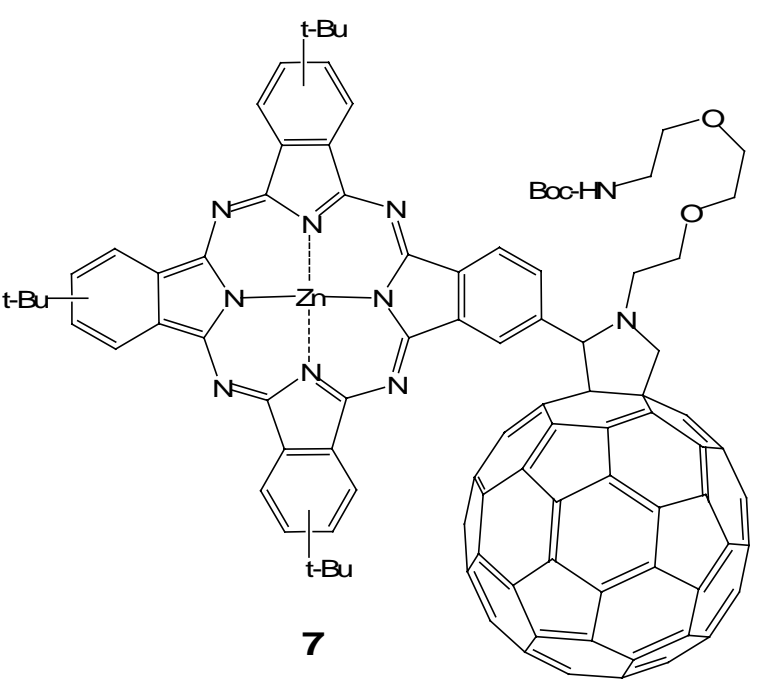

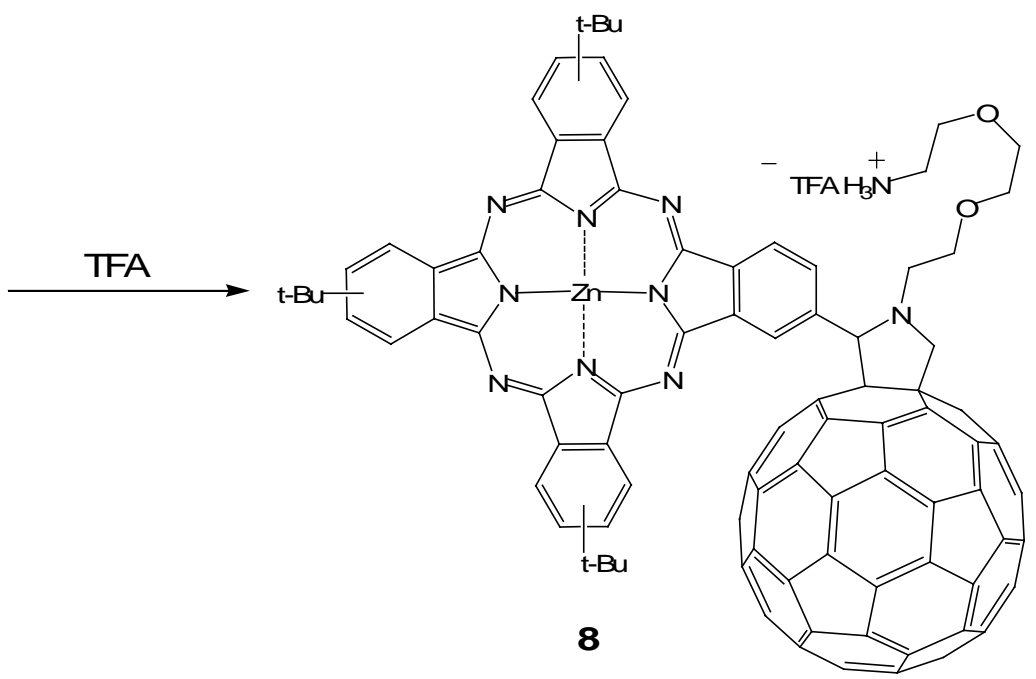

Scheme 2: Synthesis of fullerene derivatives $\mathbf{7}$ and $\mathbf{8}$

ZnPc-fulleropyrrolidine 7. A mixture of $20 \mathrm{mg}$ of amino acid $\mathbf{6}(65 \mathrm{mmol})$ and $14 \mathrm{mg}$ of pthalocyanine aldehyde $\mathbf{1}(17.8 \mathrm{mmol}) \mathrm{was}$ heated to reflux in toluene $(40 \mathrm{ml})$ in the presence of $31 \mathrm{mg}$ of $\mathrm{C}_{60}(43 \mathrm{mmol})$. After $3 \mathrm{~h}$, the mixture was cooled to room temperature and the crude product was purified by flash chromatography (toluene/ethyl acetate 9/1) giving the fullerene derivative 7 (10 mg, $5.7 \mathrm{mmol}$, yield $32 \%$ based on starting aldehyde). ${ }^{1} \mathrm{H}$ NMR $\left(500 \mathrm{MHz}, 25^{\circ} \mathrm{C}, \mathrm{CDCl}_{3}\right.$, TMS): $\delta=9.5-7.0(\mathrm{br}, 12 \mathrm{H}, \mathrm{ArH}), 5.2(\mathrm{~s}, \mathrm{NH}), 4.3\left(\mathrm{~s}, 4 \mathrm{H}, \mathrm{CH}_{2}\right), 4.1\left(\mathrm{~m}, 2 \mathrm{H}, \mathrm{CH}_{2}\right)$, $3.8\left(\mathrm{~m}, 4 \mathrm{H}, \mathrm{CH}_{2}\right), 3.5\left(\mathrm{~m}, 2 \mathrm{H}, \mathrm{CH}_{2}\right), 3.2\left(\mathrm{~m}, 3 \mathrm{H}, \mathrm{CH}_{2}\right), 1.7-1.4\left(\mathrm{br}, 36 \mathrm{H}, \mathrm{C}\left(\mathrm{CH}_{3}\right)_{3}\right) ;{ }^{13} \mathrm{C}^{\mathrm{NMR}}\left(125 \mathrm{MHz}, \mathrm{CDCl}_{3}, 25{ }^{\circ} \mathrm{C}, \mathrm{TMS}\right): \delta=156.1$, $155.0,154.3,153.4,147.6,146.5,146.4,146.2,145.8,145.6,145.5,144.7,143.3,142.8,142.5,142.4,142,140.5,138.8,137,136.3,127.5$, $122.7,119.5,79.6,71,70.7,70.5,70.3,68.5,66.3,53.3,36.3,32.3,28.5 ; \mathrm{IR}(\mathrm{KBr}): y=3423,2955,1615,1458,1394,1331,1256,1144$, $1090,1048,922,879 \mathrm{~cm}^{-1}$; Electrospray mass spectrum: (THF- $\mathrm{CH}_{3} \mathrm{OH} \mathrm{1:1):} \mathrm{m} / \mathrm{z:} 1738\left(\mathrm{M}^{+}\right)$.

ZnPc-Fullerene salt 8. The fullerene salt $8(9 \mathrm{mg}, 5.4 \mathrm{mmol}$, yield $95 \%)$ was obtained by adding an excess of TFA (1 ml) to a solution of 7 in $\mathrm{CH}_{2} \mathrm{Cl}_{2}(2 \mathrm{ml})$ and stirring overnight. The salt was precipitated and washed several times with hexane. Electrospray mass spectrum: $\mathrm{C}_{112} \mathrm{H}_{58} \mathrm{~N}_{10} \mathrm{O}_{2} \mathrm{Zn}$ (THF/MeOH 1:1): $\mathrm{m} / \mathrm{z}: 1640\left(\mathrm{M}^{+}\right)$. This compound was not enough soluble for NMR studies. 
3. IR spectrum of compound 7:

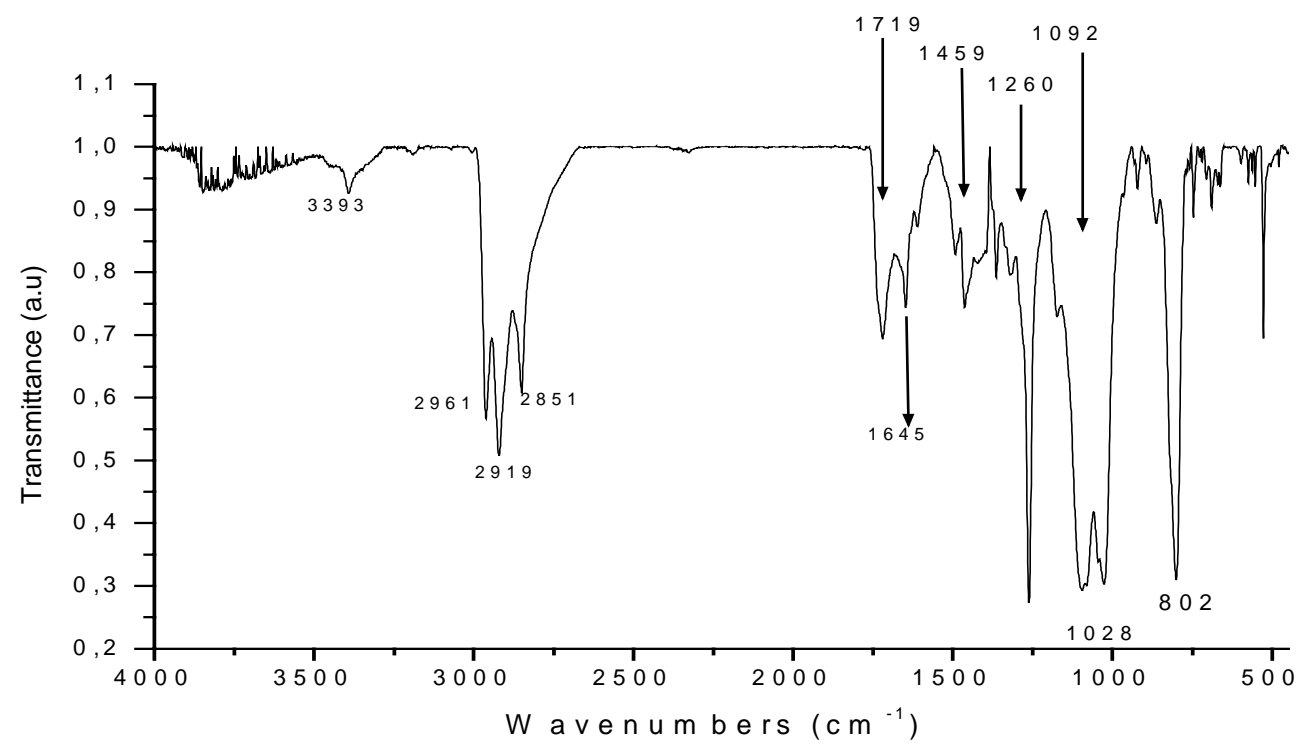


4. HPLC chromatogram of compound 7:

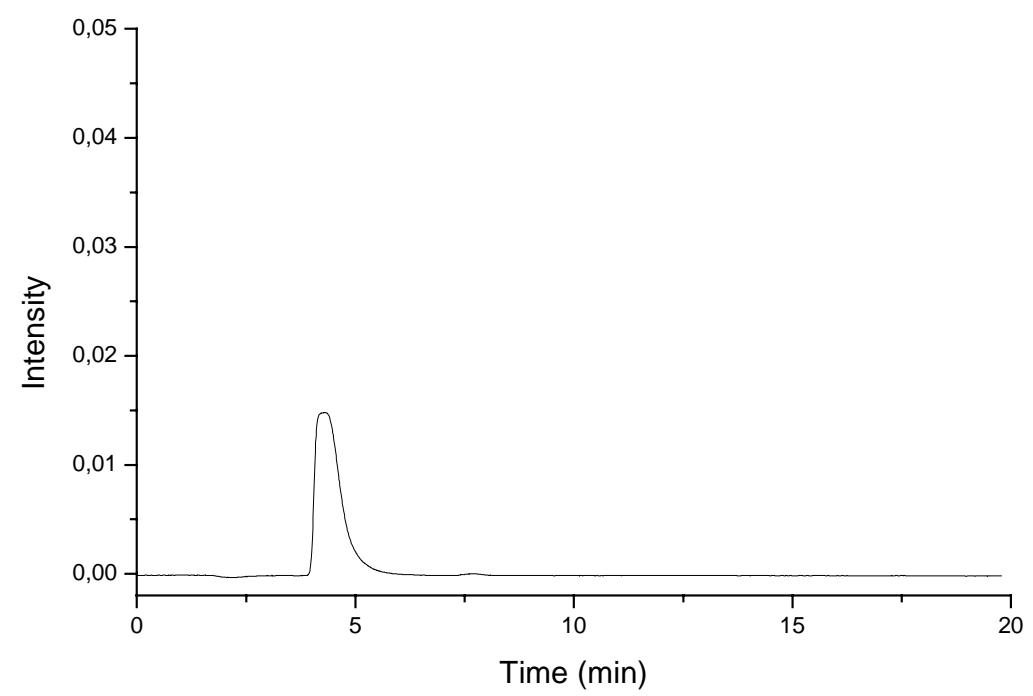

HPLC chromatogram of the product 7 in acetonitrile, flow rate $0.8 \mathrm{ml} / \mathrm{min}$, retention time $4.3 \mathrm{~min}$. 
5. Mass spectrum of compound 8:

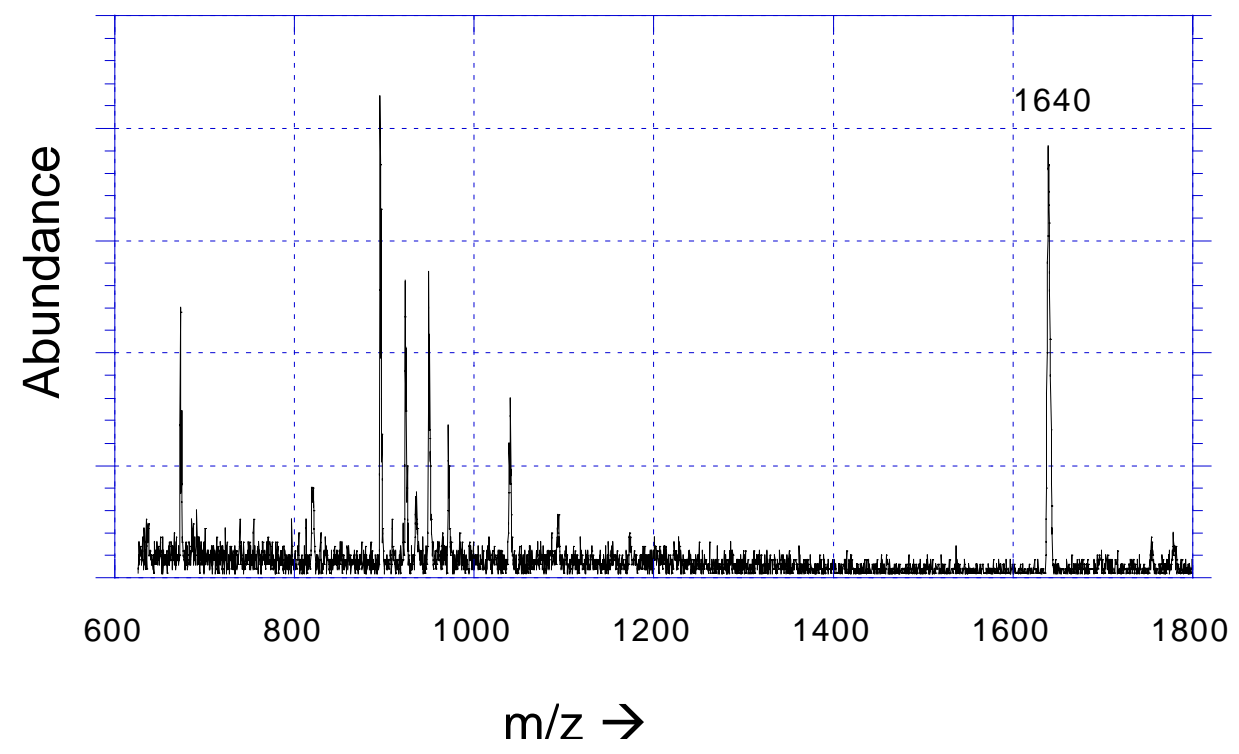


A total of $0.5 \mathrm{mg}$ of the fullerene salt $\mathbf{8}$ was dispersed in $1 \mathrm{ml}$ of filtered water (Millex-HV filter, Millipore). The mixture was sonicated three times for $10 \mathrm{~min}$ in a ultrasonic water bath with $10 \mathrm{~min}$ intervals. The insoluble material was removed by centrifugation at $3.000 \mathrm{rpm}$ and one drop from the solution was transferred to a TEM grid (copper grid, $3.0 \mathrm{~mm}, 200$ mesh, coated with formvar film) together with a drop of uranyl acetate ( $2 \%$ water solution). After air drying of the grid, TEM images were taken on a Philips TEM 208 at an accelerating voltage of $100 \mathrm{kV}$.
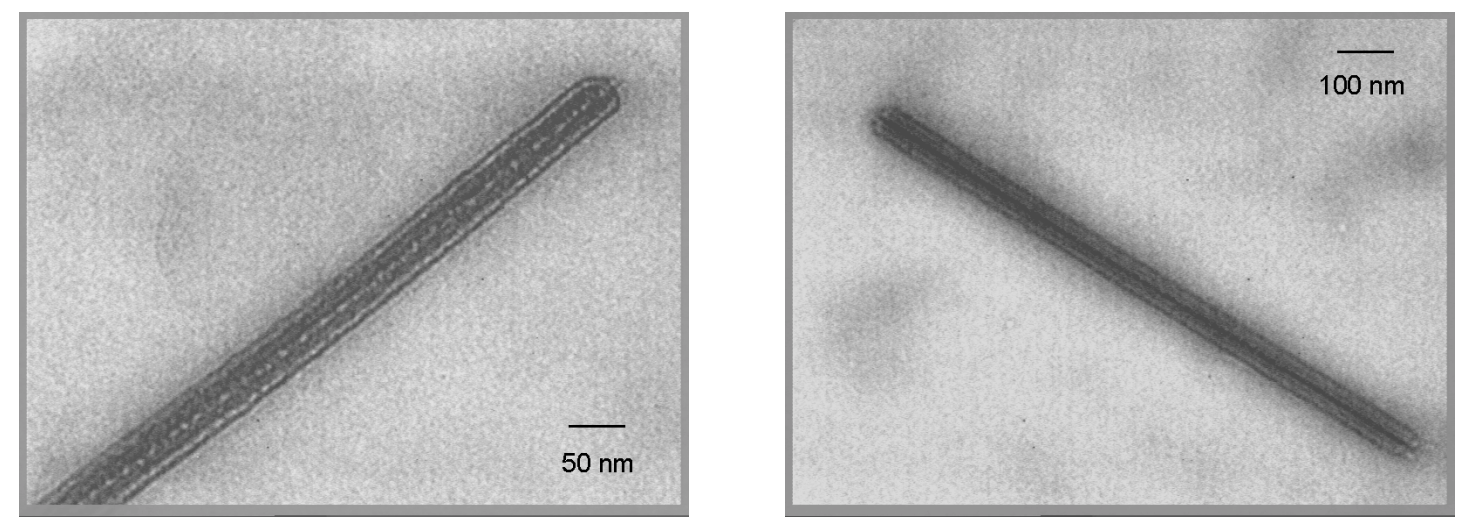

Figure S1: Nanotube formed in water solution deposited on a TEM grid 
Nanosecond laser were performed with laser pulses from a Molectron UV-400 nitrogen laser system (337.1 nm, $8 \mathrm{~ns}$ pulse width, $1 \mathrm{~mJ} / \mathrm{pulse})$ or from a Qunta-Ray CDR Nd: YAG system (355 nm, 20 ns pulse width). The photomultiplier output was digitized with a Tektronix 7912 AD programmable digitizer. For all photophysical experiments an error of $10 \%$ must be considered. Fluorescence lifetimes were measured with a Laser Strope Fluorescence Lifetime Spectrometer (Photon Technology International) with $337 \mathrm{~nm}$ laser pulses from a nitrogen laser fibercoupled to a lens-based T-formal sample compartment equipped with a stroboscopic detector. Details of the Laser Strobe systems are described on the manufactures web site, http://www.pti-nj.com. Emission spectra were recorded with a SLM 8100 Spectrofluorometer. The experiments were performed at room temperature. A $570 \mathrm{~nm}$ long-pass filter in the emission path was used in order to eliminate the interference from the solvent and stray light for recording the fullerene fluorescence. Each spectrum was an average of at least 5 individual scans and the appropriate corrections were applied. The fluorescence quantum yields were determined with a $\mathrm{ZnPc}$ reference and an average value of 3 fluorophore concentrations with ODs at the excitation wavelength ranging from 0.1 to 0.5 . 